\section{Clinitad decture}

ON THE

\section{TREATMENT OF PULMONARY CONSUMPTION.}

DELIVERED AT

ST. MARY'S HOSPITAL MEDICAL SCHOOL, DECEMBER $13 \mathrm{TH}, 1861$.

BY

THOMAS K. CHAMBERS, M.D.,

FELLOW AND CENSOR OF THE ROYAL COLLEGE OF PHYSICIANS OF LONDON; PHYSICIAN TO, AND LECTURER ON MEDICINE AT, ST. MARY'S HOSPITAL; ETC.

Pulmonary consumption affords you an admirable opportunity of studying the work of restorative medicine. You see so much of it among in- and out-patients, that you get a good general idea of the disease, uninfluenced by any accidental circumstances of individual instances; the means of accurate diagnosis at our disposal are easier of application; and the direct connection between the morbid anatomy and the symptoms more traceable than in any other class of medical cases.

I take it for granted, that in the Systematic Course of Lectures on Medicine you have had made clear to you the following propositions, which seem to me the chief points contributed by pathology to the treatment of the disease, and in proving which a great deal of time and intellect have been worthily spent.

1. That the cause of the symptoms, of the disease, of the fatality in fatal cases, is the occupation of vital organs, especially the lungs, by tubercle.

2. That the tendency which originates the formation of this tubercle, resides in the constitution of the individual.

3. 'That this tendency may be either hereditary or acquired, or both.

4. That the circumstances which quickest develope this tendency are the same as contribute to anæmia, or want of supply to the formation of tissue; namely, starvation, bad air, deprivation of light, exposure to cold without power of resistance, fatigue, previous illness ; in short, any depressant of the powers of life.

Morbid anatomy and auscultation have rendered us the enormous service of tracing out truly in death and life the organs chiefly injured in pulmonary consumption, and the nature of the injury. You have no notion what an incalculable advantage you have over your grandfathers in this respect. But you must not stop here; pathology must carry you on further, or you will have gained so little from science, that I doubt if your practice will be any better than your grandfathers', in spite of your additional knowledge. Often, during our conversations in the wards, I perceive signs of your considering the tubercle as the disease against which you have to direct the energies of your minds, and from which the patient has to be delivered. You want to do something to "stop" it, to "absorb" it, to counterirritate or evacuate it; you seem to imagine that if you could take away that mass of cheesy matter which auscultation puts as readily before your mind as if the ribs were transparent, your treatment would be perfect.

And I fear that in this you might be encouraged very often by the tone of medical literature, even of modern date. Thus I read in the Cyclopredia of Practical Medicine that emetics are useful in the early stages of phthisis, by displacing and evacuating the tubercles from the lungs. Can the writer ever have really tried with a scalpel to pick out a tubercle from the pulmonary tissue, when he thus suggests the possibility of the gentle pressure of vomiting effecting such a feat? And I find the effects of cod-liver oil sometimes attributed, not with obvious common sense to its being an oil, but to the minute traces of iodine which it contains. Nay, iodine itself has been given in long courses with the idea of causing the removal of the tubercles.

I wish to put these notions out of your heads. What the patient has to fear, is not the remaining of the tubercle in the body, but its increase. That which is once there has done its mischief, its path of ruin is past, the portion of lung which it has occupied is gone for ever, and cannot grow again any more than an amputated leg. The post mortem examinations of consumptives show almost always the cause of death to be a fresh formation of tubercle at no distant period, which has abridged the remaining organ to a degree inconsistent with life. A single deposit of tubercle to a moderate extent can almost always be recovered from. It is the continuous repetition of the process which is so fatal. I cannot, therefore, too strongly impress upon you, that not so much the tubercle as the tendency to form tubercle, not the morbid matter but the diathesis, is that which should occupy your thoughts.

When tubercle first takes its place in the pulmonary tissue, the lung feels a good deal inconvenienced by its presence; there is cough, inflammation round it, condensation of the neighbouring substance, and, from the unaccustomed loss of part of the respiratory function, there is general illhealth. These consequences are directly proportioned to the quantity of lung spoilt. They may be so severe as to cause death by what is called "tuberculous pneumonia", or by "galloping consumption", when a large extent is very quickly rendered unserviceable. Or, when the injury is slower and slighter, they may be so insignificant as not to have attracted notice at all. The other day, in a patient who died of chorea dependent on a tubercle in the spinal cord, you saw scattered tubercles in both lungs, which had caused no symptoms at all during life, though they probably had been there longer than the tubercle in the less usual situation which proved fatal. And very often in persons killed by accident, apparently in the prime of activity and with no history of any serious illness, you find crude tubercles, scars of former tubercles, and the chalklike débris of tubercular matter.* And, to come to more agreeable evidence, you find people with very large quantities of tubercle in the lungs, so large as to have proved almost fatal, who yet recover to a

* In 566 autopsies of tubercular persons, which $I$ found recorded in the post mortem books of St. George's Hospital during ten years, there was seen cretaceous matter in the pulmonary tissue in 65 . See Decennium Pathologicum, chap. v, sect. $\tau$, where statistical aing. ments are assigned for cousidering this solid substauce to be really of tubercular churacter. 
great extent from the mischief which it has caused. When once the lung has got over the shock of illness produced by the presence of the first crop, the health recovers, and the patient (though imperfect in body, of course) has only to fear a fresh development. It is astonishing what enormous ravages may be made in the lung, and yet with the help of what remains people recover the health that has been lost. I dare say jou may remember in the summer a poor woman sent to the hospital apparently to die. There was in the left upper lobe a vomica, so large that there was "metallic tinkling" in it; and for some weeks I took the opportunity of teaching you this rare sound. You know that it hardly ever occurs except in pneumothorax with perforation, and indicates a cavity bigger than your fist at least. So weakened was the patient by the loss of so much lung, that she was at first unable to feed herself even, and quite soaked the bed with colliquative perspirations. Yet, contrary to all we expected, she lost her perspirations, gained flesh, walked about the ward, and finally walked home during my absence from London, so that I cannot say what was the exact state of her chest on leaving. But I take for granted that the cavity remained unclosed, and probably will remain unclosed for the rest of her life. That it will do so for many years, I know from other cases. For example: R. S., a wine merchant, aged 42, was, in 1846, under the care of several of the most experienced in chest complaints of the London physicians. He had a large romica in the left apex, was excessively debilitated by it, and was sent home with the information that he could not live a month. Well, he picled up strength and flesh, was enabled to return to his business, and, when I saw him in 1858, twelve years afterwards, was in fair health, and as able to do a moderate day's work as any body I know; but auscultation left no doubt that the vomica was still open in the lung, and that the small quantity of pus he expectorated came from it. In 1855, I advised a young man, with softening tubercles in the left lung, to accept a chance which he had of settling in the West Indies. Six years and a half afterwards, he returned to England for a temporary purpose, and came to me about some symptoms not entirely connected with his chest. I found that his vomica was still there, and secreting pus; but that he had never permanently lost again the flesh which a course of iron and cod-oil had put upon him. He had even had an attack of hæmoptysis, and gone through yellow fever, without serious injury.

My experience of post mortem examinations leads me to the conclusion, that in cases of cured phthisis pulmonalis, vomicæ rarely heal up, but that they become dormant and comparatively innocent, lined with a thick pus-secreting membrane, and thus separated from the healthy lung around them. It is rendered most probable by the same source of knowledge, that the "chalky" masses are the remains of hard tubercle, which has dried up without softening. (See Decennium Pathologicum, in place above cited.)

As a contrast to such cases-which the way in which we lose sight of our patients prevents our multiplying-as a contrast to these where vomicæ have become innocuous, compare those in which chronic consumption proves fatal. In the latter, a dissection always (accidental cases excepted) reveals either in the lungs themselves or in other vital organs, a formation of fresh hard tubercle, as the cause of death, besides the established vomica or long existing masses of morbid matter.

It is clear, therefore, that it is the tendency to tubercle, and not the existing tubercle, which we have to fear and to guard against; and that for the successful treatment of consumption we must withdraw our minds from the morbid anatomy of the locality to the fatal propensity of the constitution.

To my mind, it is a great relief and rest to be able to map out by auscultation the exact extent of the mischief done, and to know that there is enough discovered morbid change to account for the severity of the symptoms. I feel then like a general who is acquainted with the exact position and whole force of his enemies, and is sure that the country will suffer no further loss if only they can be kept from advancing. There is no question about the future conduct of the war if only reinforcements can be stopped in their march. If the remaining portion of lung has retained life so long, it can retain life longer, and the whole attention can be applied to its conservation.

In what direction must we turn to aid in this conservation? To the lungs? But if we look to the histories of those who have lived long with vomicæ or tubercles, they are by no means found to have taken special care of their lungs-they have not coddled or lived in-doors in even temperatures, hanging their lives on to their thermometers for fear of coughs; they have gone on with their professions or business or work; they have not "laid a knife to their throat", but have eaten and drank like other people, and have enjoyed the gratification of their appetites. A patient of mine, over fifty, with copious pyoptysis and condensed lungs (probably tubercular) from his youth, has kept hounds, broken his bones like other Nimrods, contested county elections, sat in parliament, enjoyed his champagne and other good things, but never allows any doctoring of his chest. An examination of it is a favour, as a contribution to science.

The statistics of the phthisical in the two sexes corroborates this deduction. Although males are more liable to tuberculosis than females, yet they are less liable to have that tuberculosis exhibited in the lungs. (See Decenniun Pathologicum, chap. iv.) Now, in all classes, women are the least disposed to exert and expose their lungs; they are more ready to invalid themselves; and, in the lower classes, whence these statistics are taken, they do not wear low dresses or tight stays.

And what is this tubercular matter? It is not anything peculiar to the lungs, but may arise from the degenerated nutrition-the inferior development of life- of any part. Excepting my glands, many of which I can easily spare, I should prefer having it in $\mathrm{m}$ J lungs to any other portion of my body; for I know that I can live with a good deal less pulmonary tissue than nature has given me. But I cannot live with it in my brain, or my heart, or $\mathrm{my}$ alimentary canal, of which I have only one.

Leave then the respiratory organs alone, and turn your attention to the stomach and bowels, the true organs of nutrition, which will receive with open arms any care you bestow upon them.

It is truly by aid of the digestive viscera alone that consumption can be curable. Medicines di 
rected to other parts may be indirectly useful sometimes, but usually impede the recovery, which in fortunate cases takes place in spite of them.

The object at which you should aim is to get the greatest amount of albuminous food possible fully digested and applied to the purpose of the renewal of the body, at the same time that the renewing agencies are brought to their highest state of efficiency. In this way, a healthy cell-renewal takes the place of that morbid imperfect cell-renewal which appears in the shape of tubercular matter.

With this view, I avoid as far as possible all those drugs which may be classed together as "coughmedicines." I mean antimony, ipecacuanha, and squill especially. I avoid also mercury, purgatives, and neutral salts, which are debilitants. Where the heart is thin and weak, digitalis is sometimes useful, by regulating and calming its action; but, as a rule, it is injurious, by the nausea and loss of appetite which it causes.

The appetite should be your great object of care. You will often find it exceedingly deficient; and, where that happens, the mucous membrane of the stomach and bowels should be brought into a braced state by quinine and by strychnine. The latter acts quickly, and may be added to the medicines from time to time; but the former is most permanent in its effects, and should be begun at once, and continued through the whole process of medication, till the appetite equals or exceeds that of a healthy person.

Iron again you will find a most powerful ally. The increase in the hrmatine of the blood which follows its use is all-important; for thus you supply to the tissues one of the few true life-giving medicines, red blood. Begin it in small doses, and gradually increase it till you find the quantity the patient can take, and then continue to administer rather less than that, so as to leave room for an occasional augmentation according to circumstances. Where you give digitalis, make it a rule to add iron and sometimes strychnine to the dose, as you thus get the full advantage of the digitalis, and avoid some of its possible evils. Iron prevents the nausea, and strychnine cooperates with digitalis in strengthening and regulating the action of a weakened heart.

When the disgust to food is extreme, adopt the plan you so often see adopted in these wards with success, of giving milk in small and very frequently repeated doses. If you find it lie long in the stomach, and produce heartburn or acid eructations, add lime-water to it. Food has an illogical habit of arguing in a circle: it creates the desire for food-of course, by strengthening the digestive organs; and thus, after a few days of milk-diet, the patients will voluntarily ask for meat, and enjoy as a luxury that which a short time before excited the greatest disgust.

In the same way cod-liver oil will also act. It will often, like milk, create an appetite. But as a rule, especially in private practice, it is as well not to commence it too soon, as the disagreeableness of the taste and feel is difficult to get over at first, and it is much easier to take it when the appetite has begun to be renewed. Then it is not felt as a hardship even to begin, and in a short time patients will get really to like it; and they will like it, not merely as reasonable men like that which does them good, but will, irrespectively of such knowledge, find it nice to the palate. Thus children, who always object to being done good to, will still of ten take to their oil with gusto; and, as a proof that exalted reason has nothing to do with the preference, the same has been observed in animals. A clerical friend of mine had a consumptive Skye terrier, which he treated secundum artem with cod-liver oil. At first the poor beastie abhorred it, and looked melancholy before and after each dose; but in a short time he began to lick his lips after it, and, if he was forgotten, would go and beg at the door of the cupboard where it was kept.

The best sort of cod-oil is the most agreeable, the clearest, the sweetest, and the most scentless-that, in fact, which is thoroughly purified of extraneous dirt. The oil from the same fish, formerly employed by curriers, was sold for their use cheap and foul, and no doubt was quite good enough for manufacturing purposes; but it must excite a very reasonable disgust in every one but an Esquimaux, I should think, for it stinks like old train-oil. Its low price wholesale permits certain firms to spend a large sum in widely advertising it as a superior form of drug : but I strongly advise you never to prescribe the "brown oil", as the name runs; it is never beneficial where the pure oil fails, and it often and often makes the patient declare he will on no consideration take it again. The mode of manufacture which causes the difference of the "brown" and "pale" oil is described in an article of the Medico-Chirurgical Review for January 1856.

The best mode of exhibition is to give at first a teaspoonful, and afterwards two teaspoonfuls, thrice a day, floating on the quinine or iron mixture to which the patient has already got habituated. I think an ounce a day is enough to administer, and need not be exceeded. If the patient absorbs all that, you may be perfectly satisfied; and more will be apt to turn rancid, and cause indigestion-the worst enemy of the phthisical. The best time to take it is at the greatest distance from meals, as thus a sort of additional meal is gained, and food and physic are not confused; but if your patient prefers any other time, on account of taste or business, do not prevent him from indulging the fancy.

The effects of cod-liver oil become less and less a marvel, the more we know of physiology. The instinctive desire shown by all nations for an oleaginous diet, and their association of substances of this nature with ideas of happiness in all ages, show the value of a certain amount of it to man's comfort. The "butter and honey" of the prophet, used as a phrase for royal food, and the constant reference in the Bible to oil as a luxury (though it could have been no rarity in "a land of oil-olive")-these are sufficient to prove its estimation among the Hebrews. The Hindoo labourer, when he devours his gallon of rice for a meal, will spend all the pice he can get on the clarified butter of the country; and " as good as ghee !" is his expression of unqualified admiration. It was an error in Baron Liebig to state that oily foods are an object of disgust to natives of hot climates. All races of men require them and seek after them; and the taste of the Esquimaux, so often quoted, depends mainly on the abundant supply of the article which the sea places at his disposal, coupled with a scantiness of other provisions. Throughout mankind there is an instinctive appreciation of the importance of this ali- 
ment, independent of accidental differences of nation or locality. It seems felt to be, as science shows it is, a necessary material for the renewal of the tissues, and the desire for it becomes synonymous with a desire for augmented life.

An easily assimilated oil comes, in fact, into the short list of directly life-giving articles in the Pharmacopcia; for it is itself the material by which life is manifested. Hence, under its use, beneficial in. fluences are exerted throughout the whole body; old wounds and sores heal up; the harsh, wrinkled skin regains the beauty of youth; debilitating discharges cease, at the same time that the normal secretions are more copious; the mucous membranes become clear and moist, and no longer loaded with sticky. epithelium; the pulse, too, becomes firmer and slower-that is to say, more powerful, for abnormal quickness here is always a proof of deficient vitality. Such are the effects, perfectly consistent with physiology, of supplying a sufficiency of a molecular base for interstitial growth.

The addition of a small quantity of alcohol will often enable the oil to be absorbed more readily. This is a principle well understood by growers of live stock for prizes at agricultural shows, who, by the addition of fermenting grains or spirits to the animal's food, often fatten it more quickly. The addition, therefore, of wine, whisky, tiucture of orangepeel, or of any other harmless bitter, to the medicine, is rational, and may be freely conceded, if the patient finds it agreeable.

The liberal use of alcohol as a remedy or preventive is a different question. It is quite true that we do meet with cases like the following:-J. P., a butcher, remarkably strong and stout, was first attended by me for delirium tremens, which he had suffered from several times before, and was always well in the interval ; an attempt to become a teetotaller was immediately followed by galloping consumption. J. A., a brewer, came to me last year about indigestion and pimples (acne rosacea) on his nose and face: I urged him to give up brandydrinking before breakfast and between meals; and he has now developed a vomica in his lungs, of which previously there was no evidence. I confess $I$ do not think such cases mere coincidences; but I explain them not entirely as corroborative of the idea that spirit-drinking keeps off consumption. I think the alcohol acted as an anæsthetic, and kept the system from noting and exhibiting the presence of the tubercles; then, when it was left off, they acted with doubly deleterious effect on the body unaccustomed to them, and unprepared by their gradual increase to bear them. The patient is in the same position as one in whom there is a large sudden development of the morbid matter.

What should you do in such instances as the above? Should you advise resumption of drinking habits? I think not; for, though the symptoms are somewhat alleviated thereby, I doubt if life is prolonged. In the last case which I quoted, after a certain struggle with bronchitis, night-sweats, and emaciation, weight and strength are being gained under cod-liver oil and quinine, although the allowance of alcohol is reduced to what may be taken by a temperate man. Here, as before, the appetite must be your aid; the stomach must be the viscus whose health is to be your care.

To foreign travel, again, take the stomach for your guide. At the dreary time of the English year, when your patients cannot get enough light and exercise to give them an appetite, let them seek those sunny climes where the winters are the joyous time for out-of-door employment. Madeira is the best place; the next is that lovely Mediterranean shore recently annexed to France, from Cannes to Mentone; and after that come a host of localities highly puffed by their inhabitants, but with more uncertain climate. In choosing a residence for your consumptive, do not mind the average height of the thermometer, or its mean variations; but find out from somebody's journal how many days were fine enough to go out forenoon and afternoon-that is the test you require. And be careful to enforee that a right use of the climate is made. If your patients, from distaste of foreign habits, pining after home, or because they are too advanced in the disease, take to moping indoors or being overwearied by going out, the sooner they return to England the better.

Next to the stomach, the bowels claim your main care. Of course you will avoid artificial purgatives, and you must also guard against natural diarrhœa. Do not allow it to go on an hour longer than you can help. The best remedies are sulphate of copper, hæmatoxylum, and opium. Chalk mixture will sometimes act well; but, if it fail, you have lost valuable time; so, if you follow custom in beginning with it, do not be obstinate in the continuance of your remedy. The sulphate of copper may be begun in doses of one-fourth of a grain, and increased up to two grains, if required to be persisted in. The hæmatoxylum may be given as an extract from four grains up to any amount required, but should not be mixed with the copper, or you produce an ink.

You see almost daily, in the hospital, cases of consumptive diarrbœa arrested sometimes for a time, sometimes permanently, even in patients whose disease is too extensive for recovery. But, more than this, I believe that the tendency to deposit tubercle also is sometimes arrested by the causing to cease of the bowel-complaint. Just after Lady-day 1861, Miss Harriet B., aged 30, whose father and mother had both died of consumption, was placed under my care by Dr. Buckell of Chichester. She had evi. dence of a small focus of tubercle in the apex of the left lung, producing pain, dulness, and crepitation, from the partial condensation of the lung round it; but no marked pulmonary ailment. I imagine the tubercle was slowly being increased from week to week. What she complained of, however, was emaciation and diarrhœa, accompanied by the passage of pus and sometimes streaks of blood in the mucous frces. She was soon relieved of this, however; and, with a store of hæmatoxylum and copper, was able to go on a long summer visit to some friends. I examined her chest as she returned through London in September, proclaiming herself quite well and stout. To my surprise, I could detect no disease at all in the lung; so that, instead of increasing, as I had feared, the pulmonary tubercle had become dormant, solely by the cure of the bowel complaint.

\section{Additional from a Clinical Lecture, May 10th, 1862.}

A few words as to special specifics for consumption. Some years ago, Dr. John Hastings announced that "naphtha" was an infallible cure for this disease. Well, people tried it, and soon knew that it was 
only applicable at all in cases where alcohol was beneficial, and even to those patients they found the purer and wholesomer forms of alcohol in daily use were both more useful and more acceptable. All the advantages of the remedy had been in the possession of the public in a pleasanter form years ago. Determined at last to try a virgin substance -integros accedere fontes atque haurire-the same gentleman has lately announced that serpent's dung (!) now succeeds to the throne on which naphtha reigned of old. Our rude forefathers in art administered many curious things: the ashes of toads, the urine of boars, live spiders, are in their lengthy pharmacopoias. Their notion was, I believe, to drive out the devil by disgusting him. But I do not think they ever hit upon the bright thought of using the very dung of the accursed type of evil, that, as he "went out", he might say,

"That eagle's fate and mine are one,

Who in the shaft that made him die

Beheld a feather of his own,

Wherewith he wont to soar so high."

I really believe the idea is original.

Good coprologists tell us that the excreta of snakes consist mainly of lithate of ammonia-a harmless though unattractive substance, and which most persons familiar with physiology would conclude to be inert. I remained satisfied with that belief till I heard Dr. Hastings, when arraigned before a public court of justice for avaricious malpraxis in knowingly administering inert remedies, swear positively that he believed this substance to be a powerful physiological agent. The powerful physiological agent was made by dissolving (i.e., destroying) sixteen grains of boa constrictor's ejecta in a gallon of water by the addition of bromine. A Bible oath is a staggerer, and after that I could not feel justified in asserting fæces to be useless till I had tried. I procured, therefore, a sample from the Secretary of the Zoological Society, and caused to be prepared a quantity of the "solution", under the name of "mistura pythonis". You have seen me order it a good many times since in cases where, no drugs being required, I felt myself justified in so doing. But instead of half an ounce, which was stated to be so active, I have given two ounces three times a day. You have seen that its effects are exactly the same as those of so much pump-water.

Such is the fate of specifics for phthisis; ex uno disce omnes; and lucky is the public if they are all as innocent as snakes' dung.

But do not let us part without a moral, or be satisfied with merely laughing at a delusion. Remember, you are acting no better than the vaunters of new specifics when you vaguely prescribe one thing or another, even of established power, because you have heard of its being "good for consumption". The time which is lost in trying this and trying that is lost for ever. You have no right to suppose that there can be any specific for that complex morbid state which originates phthisis you have no right to substitute an experimental search after it for rational treatment; you have no right to stand in the way of the patient getting his chance of the renewal of his waning life by restorative agents.

\section{ellustrations}

OF

\section{HOSPITAL PRACTICE: METROPOLITAN AND PROVINOLAX.}

\author{
ST. MARY'S HOSPITAL.
}

PRACTICAL REMARKS ON THE PATHOLOGY aND TREATMENT OF SKIN-DISEASES,

By C. Handfield Jones, M.B., F.R.S., Physician to the Hospital.

[Continued from page 488.$\rceil$

Impetigo, though presenting some external dissimilarity, differs in no really important point from eczema, one of whose varieties is distinguished by its name. Its distinctive features are that it tends much more to assume the pustular character, forms thicker scabs, spreads less in extent, and more apparently in depth: so that spots and patches of eruption are frequently separated by a greater or less extent of healthy skin. The essentially superficial nature of the disease is, however, proved by the circumstance that the best marked cases of it recover under appropriate treatment without the surface occupied being at all scarred. Manifestly, the true skin is not ulcerated, except, perhaps, in severe cases; the discharge proceeds from the denuded basement surface of the corium.

I have carefully examined the scabs of eczema and of impetigo; and find that they both consist of the same elements; namely, epidermic cells, amorphous granular matter, and pyoid corpuscles. These latter differ decidedly in their appearance, shape, and refractive power, from normal pus-corpuscles; but when treated with acetic acid, show multiple nucleoli. The impetigo scabs differ from those of eczema in containing fewer scales, much more amorphous matter, and a greater number of pyoid globules. The latter are by no means scanty in eczema, except when it is attended with little exudation, as in cases approaching a cure. In them, the scabs are almost wholly made up of epidermic cells. The favourite habitat of impetigo is the occipital region of the scalp, especially in children; and next, the face. Like eczema, it may assume the figurate form. It is very rarely, I believe, of sthenic character; the cases commonly met with yield with remarkable facility to arsenic and dilute citrine ointment.

It is not uncommon for impetigo or eczema to coexist with more or less severe inflammution of the more superficial textures of the eye or ear. In these cases it does not seem so much that there is extension of the inflammation in one or other direction, as that the same tendency of the system manifests itself in both situations, either simultaneously, or in one or other first. Of this, the following case is a good example.

CASE IX. W. J. H., aged 3 years, was admitted March 27 th. He had been ill since Jan. 8 th; had measles be. fore. He was weak, apyretic. He had a copious eruption on the face of an eczematous character. Both eyelids were swollen and adherent; the conjunctivæ inflamed and secreting pus; he could not endure light. He was ordered to have six minims of tincture of sesquichloride of iron and four minims of chloric ether in two drachms of water four times a day; to take a drachm of cod-liver oil three times a day; and to have zinc and lead ointment applied to the face.

March 31st. The skin of the face was much improved; the inflammation of the eyes was also less; but, now that the right eye could be opened, it appeared that the cornea had partly given way, and was replaced by a fibroid tissue. 